\title{
О РАЗРЫВНЫХ НАРУШЕНИЯХ КРИСТАЛЛИЧЕСКОГО ФУНДАМЕНТА ЭСТОНИИ
}

Прямых геологических признаков разрывных нарушений в кристаллическом фундаменте Эстонии чрезвычайно мало. В качестве косвенных признаков служат установленные бурением интрузии, тектонические поднятия и некоторые другие явления, образование которых связывается с разрывными нарушениями. Известные гидротермальные рудопроявления в средней и северо-восточной частях Эстонии также связываются с тектоническими разломами неглубоких зон земной коры (Пальмре, 1971).

По мере накопления геологических и геофизических данных, сложилось определенное представление о расположении разломов в кристаллическом фундаменте Эстонии. Некоторые более крупные разломы указаны в работе Ә. Побула (1962), а также на ряде мелкомасштабных тектонических схем прилегающих территорий (Головин, 1966; Войтылова и др., 1966; Зандер и др., 1967; Полонская, Файтельсон, 1969; Файтельсон, Мишина, 1970 и др.).

Имеющийся в настоящее время геологический и геофизический материал позволяет более детально изучить распространение разрывных нарушений фундамента на территории Эстонии. С этой целью нами использованы схемы гравитационных и магнитных аномалий, составленные по данным наземных и аэромагнитных съемок различного масштаба.

Методические основы анализа геофизических полей для выделения разрывных нарушений по геофизическим признакам рассмотрены во многих работах (Тяпкин и др., 1966; Кунин, Дитмар, 1967; Симоненко, 1968; Уразаев, 1970; Крутиховская, Пашкевич, 1970 и др.)

На основе геолого-геофизических исследований можно указать следующие геофизические критерии выделения разрывных нарушений, связанные с изменением характера полей: сочленение и смена полей разного типа; торцевое сочленение различным образом ориентированных аномалий; рассечение аномалий одного простирания аномалиями другого простирания; резкая смена простираний аномальных зон, изменение их конфигурации и интенсивности; резкое ограничение аномалий; смещение их осей и контуров; системы линейно вытянутых аномалий обоих знаков; цепочки узких линейных положительных аномалий; линейно вытянутые, иногда прерывистые зоны градиентов или ступеней полей; деформация плавного характера простирания изолиний; короткие отрезки прямолинейного простирания изолиний и т. д. 


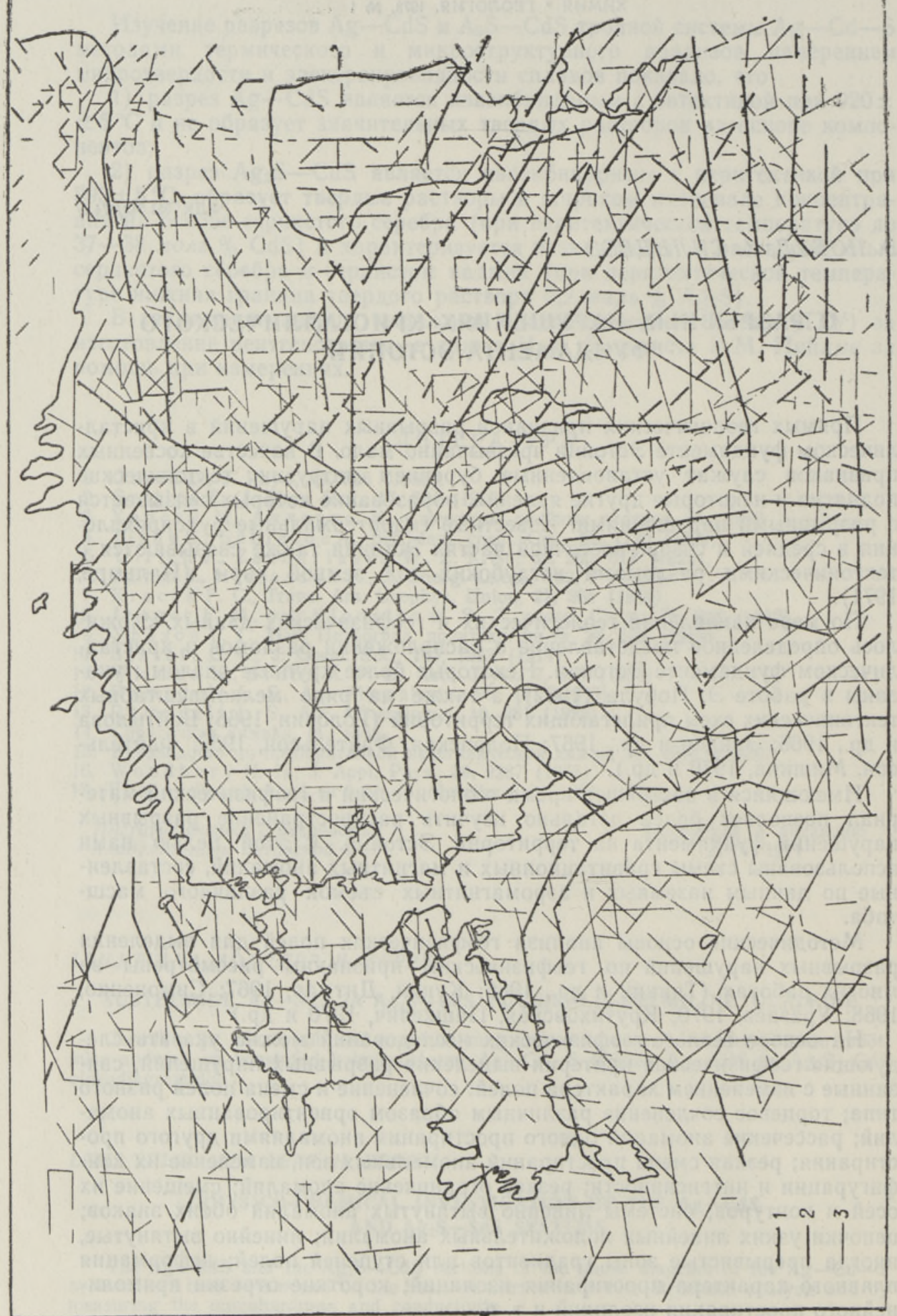

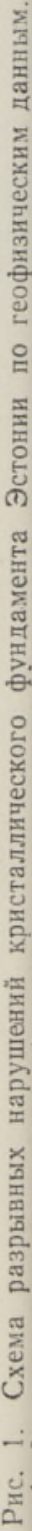




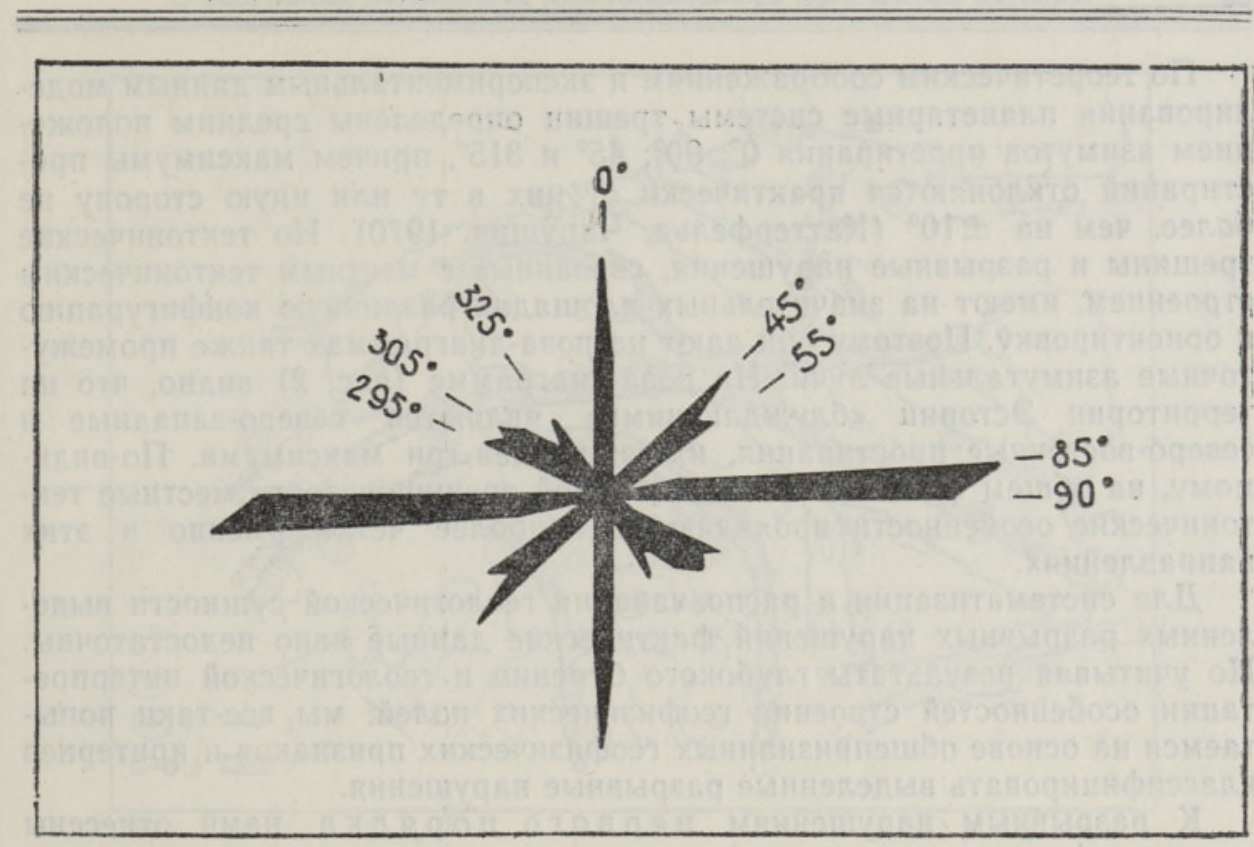

Рис. 2. Роза-диаграмма пэостираний разрывных нарушений кристаллического фундамента Эстонии по геофизическим дашным.

Для выявления разрывных нарушений необходимо, таким образом, тщательное изучение характеристик геофизических полей и их линеаментов. При этом существенное внимание надо уделять корреляции систем таких признаков.

Исходя из приведенных выше критериев, нами составлена схема предполагаемых разрывных нарушений кристаллического фундамента Эстонии (рис. 1). Большинство нарушений выделено по совпадению нескольких признаков геофизических полей. Однако нужно иметь в виду, что по детальности исходный геофизический материал, касающийся разных частей территории, неоднороден и поэтому в схеме возможны неточности и пропуски. В целом, полученная нами картина нарушений довольно похожа на картину линий разрывных нарушений Финляндии, составленную на основе топографического картирования, аэрофотосъемок и полевых наблюдений (Härme, 1961). Подобная же картина разломов докембрийского фундамента проявляется и на территории Латвии (Берзинь, Озолинь, 1970).

Анализ простираний всех выделенных нарушений фундамента показывает (рис. 2), что в Эстонии обнаруживаются достаточно четко $(90,9 \%)$ две системы взаимно перпендикулярных нарушений - ортогональная, к которой относятся меридиональные $(16,5 \%)$ и широтные $(30,4 \%)$ нарушения, и диагональная с нарушениями северо-западного $(25,0 \%)$ и северо-восточного $(19,0 \%)$ простираний. Очевидно, такая закономерность в распределении разрывных нарушений фундамента указывает на их связь с планетарной трещиноватостью земной коры, которая распространена всюду в глобальном масштабе и связана с ротационным режимом Земли (Каттерфельд, Чарушин, 1970).

Согласно С. Шульцу (1971), ориентировка тектонических структур подчинена планетарной трещиноватости. Они могут использовать готовую канву сети планетарных трещин. Складчатость так или иначе приспосабливается к первичной сети планетарной трещиноватости. 
По теоретическим соображениям и экспериментальным данным моделирования планетарные системы трещин определены средним положением азимутов простирания $0^{\circ} ; 90^{\circ} ; 45^{\circ}$ и $315^{\circ}$, причем максимумы простираний отклоняются практически от них в ту или иную сторону не более, чем на $\pm 10^{\circ}$ (Каттерфельд, Чарушин, 1970). Но тектонические трешины и разрывные нарушения, связанные с местным тектоническим строением, имеют на значительных площадях различную конфигуращию и ориентировку. Поэтому они дают на роза-диаграммах также промежуточные азимутальные лучи. На роза-диаграмме (рис. 2) видно, что на территории Эстонии «блуждающими» являются северо-западные и северо-восточные простирания, имеющие два-три максимума. По-видимому, на общем фоне систем планетарной трещиноватости местные тектонические особенности проявляются наиболее четко именно в этих наппавлениях.

Для систематизации и распознавания геологической сущности выделенных разрывных нарушений фактические данные явно недостаточны. Но учитывая результаты глубокого бурения и геологической интерпретации особенностей строения геофизических полей, мы все-таки попытаемся на основе обшепризнанных геофизических признаков и критериев классифицировать выделенные разрывные нарушения.

K разрывным нарушениям первого порядка нами отнесены разломы (или зоны разломов), характеризующиеся протяженными до нескольких сотен километров полосами больших градиентов гравитационного и магнитного полей. Эти нарушения ограничивают крупные структуры геофизических полей разного типа. Ширина зон разломов составляет обычно 10-15 км и в их пределах выделяются отдельные линейные разломы с сопровождающими многочисленными интрузиями различного состава (рис. 3). Наиболее четко выделяется зона разломов 8-8, проходяшая через территорию Эстонии в северо-западном направлении вдоль краевой части предполагаемой древней складчатой системы (Побул, 1962). О глубинном заложении этой зоны 8-8 и параллельных с ней разломов $6-6,7-7$ и 9-9 свидетельствует устойчивое расположение повышенных градиентов осредненного гравитационного поля при радиусах осреднения 10 и 32 км. Достаточно четко проявляется также зона разломов 11-11 субширотного простирания, проходящая через среднюю часть территории от о. Сааремаа до Чудского озера.

В зависимости от внутреннего строения фундамента простирания зон разломов первого порядка не всегда прямолинейны. Дугообразное очертание зон разломов проявляется четко в Рижском заливе (зона 13-13) и в юго-западной части территории (зона 12-12). Последняя зона, а также разломы $17-17$ и $18-18$ прослеживаются в южном направлении на сотни километров через всю центральную Прибалтику (Берзинь, Озолинь. 1970). Большую протяженность имеют также зоны разломов $13-13,16-16$ и некоторые разломы, прослеживающиеся в пределах территории Эстонии лишь фрагментарно. Некоторые разломы, например $1-1,2-2,3-3$ и другие, можно рассматривать как звенья более протяженных прерывистых разломов.

При пересечении зон разломов первого порядка образуются ослабленные участки земной коры с повышенной раздробленностью фундамента. Такие участки особенно часты в средней части Эстонии при пересечении зоны разломов 11-11 широтного простирания с разломами других простираний. Своеобразная концентрация зон разломов дугообразного очертания $11-11,12-12$ и 13-13 проявляется в районе южного берега о. Сааремаа. По-видимому, этот район можно рассматривать как тектонический узел с многократной активизацией тектонических процессов. 


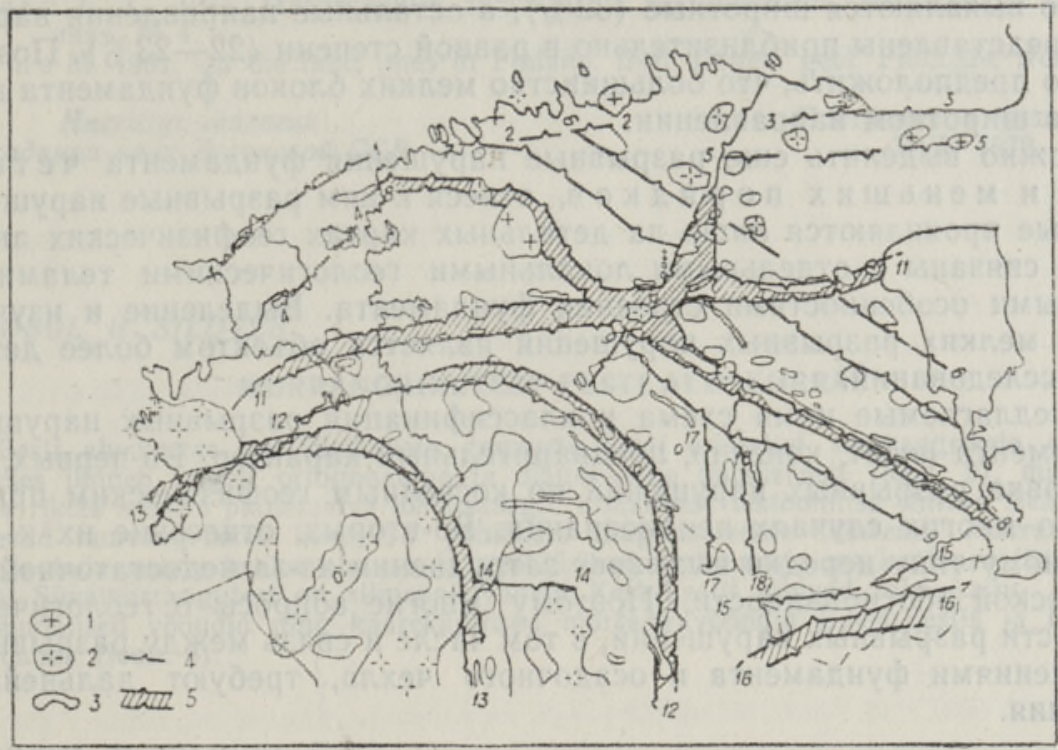

Рис. 3. Схема расположения глубннных разломов кристаллического фундамента Эстонии по геофизическим данным.

1-2 - массивы гранитов рапакиви: 1 - установленные бурением; 2 предполагаемые; 3 - предполагаемые интрузии различного состава; 4 глубинные разломы; 5 - зоны глубинных разломов.

Ко второму порядку нами отнесены отдельные разломы (или их узкие зоны) большой протяженности, геофизические признаки которых проявляются весьма четко, но с меньшей интенсивностью, чем в зонах разломов первого порядка. Большинство их расположено параллельно зонам разломов первого порядка и также связано с основными структурами кристаллического фундамента. Әти разломы разделяют фундамент на крупные блоки. Нередко разломы второго порядка сопровождаются интрузиями различного состава, что свидетельствует о глубоком их заложении. По распределению простираний выделенных разрывных нарушений первого и второго порядков преобладающими являются северо-западные $(40 \%)$ и широтные $(32 \%)$ нарушения, а северо-восточные $(15 \%)$ и меридиональные $(13 \%)$ нарушения являются подчиненными. Это объяснимо, очевидно, преобладающим простиранием складчатых сооружений фундамента.

Разломы первого и второго порядков можно сопоставить, по классификации М. Чирвинской (1966), с разломами глубинного заложения (подкоровые) или с разломами глубокого заложения (коровые).

К т ре ть е м п п р я д у отнесены остальные выделенные разрывные нарушения фундамента различного простирания и небольшой протяженности. На региональном плане как в ортогональной, так и в диагональной системах они имеют вид длинных, прерывистых, часто кулисообразно смещенных линий. Такое направленное расположение разрывных нару. шений явно свидетельствует о том, что они приурочены к первичной планетарной трещиноватости земной коры. Генетически эти разломы связаны, по-видимому, с тектоническими процессами, происходившими глав ным образом в поверхностных частях коры, и поэтому имеют неглубокое заложение. Разломы третьего порядка разбивают крупные блоки на мелкие. Среди нарушений третьего порядка, связанных в основном с местными особенностями тектонического строения фундамента, наиболее 
сильно выявляются широтные $(32 \%)$, а остальные направления нарушений представлены приблизительно в равной степени $(22-23 \%)$. Поэтому можно предположить, что большинство мелких блоков фундамента вытянуто в широтном направлении.

Можно выделить еще разрывные нарушения фундамента четвертого и меньших по рядков, отнеся к ним разрывные нарушения, которые проявляются лишь на детальных картах геофизических аномалий и связаны с отдельными локальными геологическими телами или местными особенностями строения фундамента. Выделение и изучение таких мелких разрывных нарушений является объектом более детальных исследований.

Предлагаемые нами схема и классификация разрывных нарушений фундамента носят, конечно, предварительный характер. Во-нервых, расшифровка разрывных нарушений по косвенным геофизическим признакам во многих случаях неоднозначна. Во-вторых, отнесение их к тому или иному типу нередко вызывает затруднения из-за недостаточной геологической обоснованности. Поэтому многие вопросы о геологической сущности разрывных нарушений, в том числе и связь между разрывными нарушениями фундамента и осадочного чехла, требуют дальнейшего изучения.

\section{ЛИТЕРАТУРА}

Бер зинь Л. Э., О золин ь Н. К. 1970. Строение фундамента территории Центральной и Западной Латвии по геофизическим данным. В сб.: Нефтепоисковые критерии Прибалтики, вып. 8. Вильнюс.

В ой тылов а Т. Н., И в а но в а Л. Н. Мож а ев Б. Н. 1986. Структурно-тектоническая схема осадочного чехла Северо-Запада Русской платформы. В сб.: Вопросы разведочной геофизики, вып. 5. Л.

Головин И. В. 1966. Использование геофизических данных для изучения геологического строения кристаллического фундамента Северо-Запада Русской платформы. R сб.: Вопросы разведошной геофизики. вып. 5. Л.

З анде р В. Н., Т ом ашун а С Ю. И., Бе рк ов ски й А. Н. и др. 1967. Геологическое строение фундамента Русской плиты. Л.

К ат терфельд Г. Н.. Ч а у шин Г. В. 1970. Глобальная трещиноватость Земли и других планет. Геотектоника, № 6.

К рут и хов ская З. А., Пашкев ич И. К. 1970. Некоторые результаты исследований связи магнитного и гравиташионного полей с тектоникой Украинского щита. Геофизический сборник АН УССР. вып. 38. Кнев.

К ун ин Н. Я., Д и т м а р В. И. 1967. Выделение тектонических нарушений и блоков по геофизическим данным в нефтегазоперспективных впадинах Южного Казахстана. В сб.: Тектоника нефтегазоносных впадин Средней Азии и Казахстана. М.

Пальм D X X. 1971. O некоторых рассеянных элементах в галенитах и сфалеритах Эстонии. Изв. АН ЭССР, Хим. Геол., 20, № 1.

Побул Э. А. 1962. О строении кристаллического фундамента Эстонии по данным геофизики. Тр. Ин-та геол. АН ЭССР, $\mathbf{X}$.

Полонская Ю. Б., Фа йтельсон А. Ш. 1969. Основные черты тектоники области Рижского залива по геофизическим данным. В сб.: Вопросы региональной геологии Прибалтики и Белоруссии. Рига.

Симоненко Т. Н. 1968. Проявление зон разломов земной коры в магнитном поле. Геофизический сборник АН УССР, вып. 26, Киев.

Тяпкин К. Ф., Нечаев В. А., Харитонов В. Д. и др. 1966. О тектонике Украинского щита ло геолого-геофизичесқим данным. Геотектоника, № 2.

у раз а е в И. М. 1970. Характеристика разломов востока Русской платформы, выявленных по магнитным и гравитационным аномалиям. В сб.: Выявление и трассирование разломов по геофизическим аномалиям Волго-Камского края, вып. 21. М.

Ф а й т е л ь с о н А. Ш., М и ш и н а А. Д. 1970. Результаты и направление геофизических исследований в Прибалтике. В сб.: Нефтепоисковые критерии Прибалтики и методы их изучения, вып. 8. Вильнюс.

Ч и р в и.н ск а я М. В. 1566 . О классификации разрывных нарушений территории Украинской ССР (по геофизическим данным). Геофизический сборник, АН УССР, вып. 15. Қиев. 
Шульц С. С. 1971. Планетарные трещины и тектонические дислокации. Геотектоника, № 4.

$\mathrm{H}$ ä rme M. 1961. On the fault lines in Finland. Bull. Comm. geol. Finlande, No. 196.

\section{Институт геологии}

Академии наук Эстонской ССР

\section{Поступила в редакцию} 3/VII 1972

\section{E. POBUL, H. SILDVEE}

\section{MURRANGRIKETEST EESTI ALUSKORRAS}

Eesti aluskorras geofüüsikaliste tunnuste järgi eristatud murrangrikete (joon. 1) jaotuses ilmneb selgelt ortogonaalne ja diagonaalne ristsüsteem (joon. 2), mis osutab nende rikete seosele planetaarse lōhelisusega. Kohalikest tektoonilise ehituse iseärasustest olenevad murrangrikked kuuluvad pōhiliselt diagonaalsesse süsteemi. Murrangrikkeid vōib jaotada nende leviku ulatuse ja geofüüsikaliste tunnuste markantsuse järgi kolme järku. Süvamurrangutest on silmapaistvamad Kesk-Eestit läbivad loode-kagu- ja lääneida-suunalised vööndid ning kaarekujulised murranguvööndid Edela-Eestis ja Riia lahe piirkonnas (joon. 3).

\section{E. POBUL, H. SILDVEE}

\section{ON FAULTS IN THE BASEMENT OF ESTONIA}

In the distribution of the faults occurring in the Estonian basement, defined on the basis of geophysical evidence (Fig. 1), we are obviously dealing with an orthogonal and diagonal system (Fig. 2), which points to those faults being connected with global jointing. The faults depending on local structural peculiarities belong mainly to the diagonal system. The faults may be divided according to the range of their distribution and to the extent of geophysical evidence into three groups which express the spatial extension of the faults. The most striking deep faults pass through Central Estonia in zones of a NW-SE and W-E direction; besides, there are arched fault zones in Northwest Estonia and in the vicinity of the Gulf of Riga (Fig. 3). 